\title{
Vulnerability and Disaster Resilience at Household Level
}

\author{
Namita Poudel ${ }^{*}$
}

\begin{abstract}
Many development practitioners, academicians, development institutions and organizations, are attempting to discover the characteristic of resilience in Nepal. The issue of disaster resilience got its prominence in Nepali scholarship after the 2015 earthquake. The people of Nepal today, are visible to perpetual disaster events and profound vulnerability to the disaster, which was already there. Disaster incidents are increasing day by day, due to natural hazards such as landslides, floods, and humaninduced activities like road accidents, fire, etc. But these consequences are not merely natural events; they are social events as well. The deaths of people, injuries, and property damage are related to the social side of the disaster. Similarly, natural hazards such as earthquakes are also creating disasters because of vulnerability and the absence of disaster resilience in Nepalese people. Rising incidents of disaster vulnerability and resilience is increasing concern of the state, academia and local level, since Nepal is 4th and 11th vulnerable to the risk of climate change and earthquakes in the world. Apart from that, other chances of disaster are equally mounting, and the capacity to cope (Resilience), or coming back to usual conditions is not enough for surviving and moving forward.

This article tries to explore the relationship between vulnerability and disaster resilience, and the research questions of this article are, what types of vulnerability are creating the barrier for a resilient household and what are the attributes of a resilient family? Dhugin, Lamatar is the field for this research, and answers are dug out based on the Nepal earthquake 2015 as a major disaster of Nepal. Field data are collected after finalizing the purposive sampling. The interview method is used to take the depth information. Face-to-face interviews with informants remained the primary sources for data collection. And this research has been conducted using a qualitative method. My finding is: adopting capacity with the help of resources and assets and absorbing capacity by shifting occupation; after a disaster are the attributes of resilient households, whereas geographically vulnerability, exclusion, poverty remained barriers for resilient families.
\end{abstract}

Key Words: Disaster, Resilience, Vulnerability, Nepal Earthquake 2015

\section{Introduction}

${ }^{*}$ Ms. Poudel has completed M.Phil. in Sociology from Tribhuwan University. Now she is a part time teacher at Saraswati Multiple Campus. Apart from that, she has been working as a sociology faculty in NATHM. 
Resilience is defined as the amount of change that a system can undergo while still maintaining control of its structure and function, or the system's ability to self-organize and the degree to which the system is capable of learning and adaptation (Carpenter and Gunderson, 2001). Resilience plays a vital role in disaster preparedness, during a disaster and post-disaster. Disaster, a disruption of the social structure and disturbance of all or some of the essential functions of society (Fritz, 1961). Nepal is facing various sorts of natural and human-induced disasters for a long, due to its geographical location, unplanned infrastructure development, and growing urbanization (GOON, 2018). For example, earthquakes, floods are natural disasters according to the government of Nepal, whereas road accidents, fire, lab explosions are human-induced disasters. In this article, among all disasters, the Nepal earthquake 2015 is taken for research to know the vulnerability and resilience. Also, sociological lenses is used to explore vulnerability and resilience because all disasters bring social disorder. Moreover, disasters are selfsocial. For instance, Japan is a resilient nation for earthquakes because earthquake resistance houses have been built everywhere. Earthquakes come and goes, and it doesn't disturb the people's everyday routine. And in Nepal, it is tremendous because of infrastructure, which is also social. Disaster is not automatically turned into a disaster, when; hazards are not addressing properly, hazards turn into a disaster. Any hazard, to become a disaster, has to affect a vulnerable population (Silwal, 2017). This paper tries to explore how households build resilience, knowing the characteristic of a resilient household. At the same time, researchers try to discover how vulnerability creates barriers for the household to be resilient after any disaster.

To understand, attributes of disaster resilience and vulnerability as a barrier to resilience, it is important to go through reviews. Additionally, skipping disaster doesn't give the sound concept of resilience because, in the whole article, resilience is attached to disaster. Thus, I am going to start the review from disaster and end with vulnerability in review part. In between, I also try to show the relationship between vulnerability and resilience.

\section{Understanding the notion of Disaster, Resilience, and Vulnerability}

Disasters are divided into "natural" and "man-made," still, such distinctions are generally artificial because all disasters are fundamentally human-made. Also, it is social order where and how people choose or forced to live. For instance, if any family is migrating Jhapa to Kathamndu, they prefer to choose the location, where majority of Jhapali are already migrating and living. Again, moving towards disaster, the trigger may be a natural phenomenon such as an earthquake, but its impact governed by the prior vulnerability of the affected community (Redmond, 2005). Although definitions vary (Quarantelli E., 1998), disasters are conceptualized as natural or human-made 
events that cause sweeping damage, hardship, or loss of life across one or more society strata. Disasters typically strike swiftly, but it can take years to recover from them. In recent decades the number of natural disasters recorded the world has risen dramatically. Between the 1960s and 1980s, there has been a fivefold increase in the number of major disasters because of development processes, including road built, infrastructure, and new technology. We can take the example of excavator use in Nepal, and its result is a landslide. There is also evidence to suggest that natural disasters are taking an increasing toll on human life and that great regional disparity exists in the type and magnitude of losses experienced. (Degg, 1992).

During a normal lifespan, most people are confronted with number of unexpected events. Accidents happen, loved ones die, health gives out, money disappears, or property is damaged. These events can be distressing and, for some, debilitating. Fortunately, most people are usually able to survive isolated in such events with no lasting psychological damage (Bonanno, 2004). But then, sometimes there are disasters. Nepal is at risk from different disasters due to natural hazards. Every year, on average of more than 500 various disaster incidents occur, resulting in loss of physical infrastructures and human life and affecting livelihood. In the last 45 years (1971 to 2015), more than 40,000 people have lost their life due to disasters. This number is more than two persons losing lives every day. These disasters have become a severe burden on the people and the community all over Nepal. In the majority of the districts of Nepal, disasters occur recurrently, where more than $90 \%$ of the populations are at high risk of death due to two or more than two types of disasters (Government of Nepal, 2018).

In such a context, to save life, property, and environment, 'must need resilience. The resilience approach emphasizes the capacity to cope with uncertainty and surprises while maintaining overall system persistence, and also resilience is about learning from error how to bounce back in better shape. A strategy of resilience involves building up institutional structures, and human resources. These are the first and last requirements of a system able to absorb, learn from, and modify it for changes. A resilience strategy entails developing coping capacity, which is arguably a better approach to adaptation given scientific uncertainty (Barnett, 2001).

To understand the concept of resilience more clearly, this added definition helps the reader. Resilience as a resilient social-ecological system incorporates diverse mechanisms for living with learning from change, and unexpected shocks ( Adger, et al. 2005). He further explains that social and ecological vulnerability to disasters and outcomes of any particular, extreme event is influenced by the buildup or erosion of resilience both before and after disasters occur. Resilience focuses on the capacity to 
cope with uncertainty. They present a timeline for characteristics of a resilient community, comprising three stages: pre-disaster ability to absorb the shocks of hazard impact, post-disaster, immediate relief, including the capacity to bounce back during and after a disaster; and a post-disaster reconstruction phase of building resilience. In the whole process of resilience, vulnerability often creates obstacles against resilience. Vulnerability, in particular, is made up of the distinctiveness of a person or group and their situation, which influences their capacity to anticipate, cope with, to resist, and to recover from the impact of a natural peril (Rai, 2017). Disasters are a result of hazard and vulnerability. The most vulnerable group consists of financially disadvantaged and low-income families, marginalized and socially excluded communities, women, children, the elderly, and people with disabilities (MoHA, 2018). Vulnerability can be defined as the diminished capacity of an individual or group to anticipate, cope with, resist, and recover from the impact of a natural or human-made hazard. The concept is relative and dynamic. Vulnerability is most often associated with poverty, but it can also arise when people are isolated, insecure, and defenseless in the face of risk, shock, or stress (IFRC, 2015).

In addition, vulnerability is determined by historical, political, cultural, and institutional, and natural resource processes that shape the social and environmental conditions people find themselves existing within. To illustrate this concept, Sindhuplachok is places, where people don't want to migrate from there even though the government is supporting them because their ancestors were there. They are historically bounded to live there although, landside and their life risk are high. It is creating vulnerability. On the other side, in the name of development, the unplanned urbanization process increases where, politics is playing a vital role. These processes produce a range of immediate unsafe conditions such as living in dangerous locations or poor housing, ill-health, political tensions, or a lack of local institutions or preparedness measures (IFRC, 2015).

People differ in their exposure to risk due to their social group, gender, ethnic or other identities, age, and other factors. The vulnerability may also vary in its forms: poverty, for example, may mean that housing is unable to withstand an earthquake or a hurricane, or lack of preparedness may result in a slower response to a disaster, leading to greater loss of life or prolonged suffering. The reverse side of the coin is capacity, which is available resource to individuals, households, and communities to cope with a threat or resist the impact of a hazard. (IFRC, 2015)

Analyzing the vulnerability involves identifying threat and 'resilience' or responsiveness in exploiting opportunities. It also includes resisting or recovering from the negative effects of a changing environment. The means of resistance are the assets and entitlements that individuals, households, or communities can mobilize and manage 
in the face of hardship. Vulnerability is therefore, closely, linked to asset ownership. The more assets people have, the less vulnerable they are, and the greater the erosion of people's assets, the greater their insecurity (Moser C., 1998). Till here, the reader can understand the notion of disaster, vulnerability with resilience. So, research is conducted to seek the answer of the following question:

Understanding the notion of disaster, vulnerability, and resilience gives clear ideas about their meaning and types. Literature also illustrates vulnerability bring disaster and reach near to how people can back to normal life after the disaster as Barnett, quote strategy of resilience, coping capacity, which is arguably a better approach to adaptation. I found the gap between that 'near' and 'how' because it doesn't talk about what type of people can back to normal life quickly. Also, literature speaks about vulnerability are barriers to resilience and the main gap is what vulnerability are barriers to resilience. So, my research woven around these gaps. Research question

a) What are the attributes of household resilience (disaster)?

b) What types of vulnerability are creating a barrier for a resilient household?

c) How vulnerability is interlinked with disaster resilience?

\section{Methodology and Data Source}

This article is written based on primary data yet, the secondary source of information is, of course, vital in the development of the conceptual arguments. Dhugin, Lamatar is the field for this research, and answers are dug out based on the Nepal earthquake 2015 as a major disaster in Nepal. The reason behind choosing Dhugin as a field is it is the most effective area of the 2015 earthquake. Another area like Barpak, Sindhupalchowk was frequently taken as the name of the most significant place. But, being closed to capital and effected, it was unseen by researchers. So, I decided to choose Dhugin as a field to bring uniqueness, to meet the research goal, and to explore how people cope and stand up in everyday life. Similarly, if they are unable to back to normal life, what are the barriers for them? Field data is collected after finalizing the purposive sampling and the purpose of choosing the informant is, I have gone through only the most affected household to meet my research goal. The interview method used, to take the depth information. During the month-long field visits, I observed first-hand material damage created by the earthquake in the Dhugin area. And this research has been conducted using a qualitative method. In every interview, informants were allowed communicate speak without any interruption. When they stop to talk, the researcher encourages them to speak more, adding some phrases like then. All answers were noted down in the notebook. The interview was taken with 22 sample 
households out of 60 houses in DhuginTole. One member of each household participated in the interview questionnaire, whereas other members of the family also answered as per their interest. After collecting data from the field and based on answerers noted in the notebook, I have done table work to analyze the data.

\section{Theoretical Review}

Literature reviews illustrate that resilience is individual or community capabilities to get back to normal life. Additionally, reviews show that vulnerability often creates a barrier to resilience. So, resilience, vulnerability, and capabilities are interlinked. Amartya Sen's initially describe five components of the capability approach. Among the five components, two components motivate this research to see from a theoretical angle. The first component is individual differences in the ability to transform resources into valuable activities. After a disaster, people need individual capabilities to use their resources. If they have abilities with them, they may go back to normal life soon. Utilizing the resource whatever they have, such as income, land, house, cash, social capital, and their skill, is the best way to build resilience and this is a capabilities approach. Second is the multi-variate nature of activities giving rise to happiness? Because of the different nature of people, some people are resilient and tackle difficult situations even they don't have anything enough which includes land, house, cash, social capital, and family members. At the same time, some people fail to gain resilience, even having material and non-material things, which also includes social behavior, and their values in society. Sen illustrates it within the capability approach. In this research, assets such as land, cash, commodities incomes, social capital, and social values help us create resilience. On the other side, poverty remained a barrier for vulnerabilities. So, research shows that, vulnerability and resilience are interlinked, and capabilities create an environment to be resilient in difficult situations such as disaster time. My research helps us to assemble how Sen's capability approach to link with resilience. The terms capacity and flexibility are commonly connected with positive implications. Capability describes a person's ability to do or achieve specific desired functioning (Sen, 1993), and resilience, some scientists apply the concept of resilience to social systems. Social resilience defined as the ability of groups or communities to cope with external stresses and disturbances resulting from of social, political, and environmental change (Adger 2000).

All formulations of the capability have two parts, freedom and valuable beings and doings (functioning). At the time of the disaster or before the disaster or else postdisaster, people need to be free from worries of dying or any kind of damage, so they need the freedom to live to be tension-free. In this context, they need the capacity to cope (resilience) to live in freedom. The capability set is the set of the vectors of 
functioning. That we very concretely do, the time is unspecified, they became specified when we focus on a particular problem. Similarly, while concentrating on the part of resilience, people may shape their life with a feeling of security to disaster, this is capability approach.

\section{Vulnerability and Resilience}

After reviews, providing theoretical ideas and methodology, I am taking the readers towards the analyzing section. In this section, I attempt to explain what types of households can get back to normal or resilient households. Similarly, the following section describes what types of vulnerability remained a barrier for the resilient household.

\section{Attributes of household resilience in Dhugin}

On Saturday, 25 April 2015 at 11:56 local time, a 7.6 magnitude earthquake recorded by Nepal's National Seismological Centre (NSC), struck Barpak in the historic district of Gorkha, about $76 \mathrm{~km}$ northwest of Kathmandu. Nepal had not faced a natural shock of comparable magnitude for over 80 years. Among the 14 most earthquake-stricken place of the country, Dhugintole is one of the most affected areas of Lalitpur district. To understand the attributes of household resilience, the researcher concerns about people's everyday life, their social structure, as well as other social sides. The following attributes of household resilience is derived from the field.

a) Resource and asset as the absorbing capacity of Household: Absorbing capacity of shock is not come automatically. Having resources and assets is one of the courage for people to build back better and field report shows that three out of 22 respondents claimed that if they are resilient today only because of they use their asset and available resource. Asset and available resources illustrate that family's income, commodities, land, cash, etc. The PDNA report says that families are deploying different coping mechanisms to deal with the disaster, including sales of assets and receipt of remittances. Indeed, three households of Dhugin follow the same way to be resilient to disaster. Mr. Naniram Ghimire reported that he sold his land to build houses, and for the education of his children. If he has not sold his property, he had to bear the big amount of loan. He still has a loan, but in comparison to other neighbors, that are very less. Similarly, PurnaPoudel also left his job to get the money that means he uses the available resource to build a safe house. At the same time, he sold the piece of land too, because he received money from a resigning job that wasn't enough to build a threestory house.

About resilience, assets are an essential part of the response to hazards. The coping mechanisms are distinguished by being reactive, and geared towards survival 
and field observation also shows a similar report. Asset owner (landowner) seems more resilient in comparison to landless and low-income households. At the household level, property titling, and security of tenure, particularly ownership of homes, will increase the likelihood of willingness to invest in longer-term adaptive mechanisms, as will other means of securing investments, such as insurance, especially for disaster time. However, for those who work in the informal sector, lacking job security or social security protection, physical assets can act as a safety net while intangible assets can provide essential social and moral support.

Land, fixed assets, strongly built houses, salary, cash are the assets for the local people. Fixed assets like land which can sell or which can be used to take a loan from a bank. Also, land can be used to re-structure and make vegetable garden or paddy. Therefore, landowners seem more resilient because of the multiple uses of land. Households gather the courage to get back to normal life with the help of fixed assets. Additionally, strongly build house save the people during a disaster and nothing happen also means attributes of resilient. While analyzing the caste wise comparison with three castes, Brahmin, Newar, and Dalit received different results. Mr. Ghimire, who has built houses, has a good status in society, also a good network in, and outside the community and now he needs a four-wheeler as an asset. Also, he wants to elect a member of the municipality to work much more in the field of disaster. Pointing to the government's mistake, he wants to do something for the community by winning the election. Generally in Nepal, ruling nature can be observed in Brahamin community. We can see the fossils of ruling nature in Dhugin too. Assets and resources are not only property also the good status in a community as well as one of the attributes of household resilience to disaster. Field result shows that households bearing strong resource and asset can absorb disaster shocks.

b) Shifting Occupation as the process of adopting shocks: Adoption capacity can be measured in various ways and among them, research drags the data that shifting occupation after a disaster is one of the adaptive capacity in the Dhugin area. Because disaster destroys many things such as occupational place, social structure, and top of that, it adds many responsibilities. To build the infrastructure, most of the victims borrow the loan from banks, and traditional occupation wasn't enough so that seven members of each household decided to change the occupation. Three Pariyar brothers thought that tailoring couldn't afford their heavy loan to leave the tailoring job, they are working in factories.

Shifting occupation from traditional (Tailoring) to wage labor is one of the challenges because they are not only leaving their occupation also they are diverting their skills which they have been followed for ages. Adaptive capacity helps them to get rid of their poverty and became resilient towards disaster. On the other side, talking 
about Brahmins, were limited in the agriculture and service sector. But, aftermath, selling the land, they started investing in the business to earn more. They also provided a similar response in the interview that they can't afford everything from agriculture. Therefore, they started a new way for subsistence and other facilities. Also, female used to work only for a house or connected constantly in the family unit errands and dealing with children. However, because of money related obligation to family, they are working in wage work as well so they can share the budgetary burden with other family unit individuals. As they don't have advanced education, they are working for modest wages. Females from all cast changing their occupation from non-beneficial to gainful with that degree of independence, which is ultimately heading towards a resilient female in Dhugin.

\section{Vulnerability}

As my second concern, how households remain vulnerable to disaster, I have received the following vulnerability from residents of Dhugin.

\section{a) Poverty}

Poverty remains one of the significant reasons for vulnerability to disaster in Dhugin area. A rich, middle, and low income household were observed. Basically, without intention in this research caste system was also involved though it was not research purposes. The caste system remained one of the components of vulnerability of poverty.

Brahmin families considered themselves that they belong to the rich family, although, they have fear that their physical infrastructure is not good enough for disaster. All sample households from the Brahmin community were somehow managing their lives with two meals (Dui Chak), proper dresses, and regular health checkups, yet they are not getting other facilities such as health posts, and schools nearby. On the other hand, one could easily observe uncleaned dresses as symbols of poverty around Dhugin. Low-income rates within the Dalit community are another reason for vulnerability. Mrs. Pariyar works for only five rupees per one Pasimina beads, whereas driving for the whole day gets only Rs 600, Mr Pariyar said. It is inadequate to feed five members of the family. Furthermore, spending a whole day in a shop, one can earn Rs 400, which is also insufficient for two meals. Low-income rate remained one of the reasons of poverty in the Dhugin area, which ultimately pushed them towards poverty vulnerability. Therefore, they couldn't think more than two meals. They are still living in half-completed houses, and half of the parts need to be constructed. In this context, they are failed to cope with the situation. They are unable to be resilient further for upcoming disasters as they don't have disaster preparedness. 
Political Instability and insecurity are another reason, which was observed during the field survey as part of vulnerability. Every time people are blaming the government, which fails to help their people in the disaster time. Our country is not well managed, doesn't care about its people, even we don't have citizenship, are answers received from Mr. Bishokarma. Twelve respondents blamed their vulnerability due to political instability and insecurity.

It's a small village, so whatever they produce, is tough to receive a proper customer. Lack of an appropriate market for the assembled products from in their area, is another sign of vulnerability in Dhugin. The poor condition of Industrial sectors also one of the reasons for poverty. If factories, industries remained in their area they may get a chance to work in higher-paid jobs, or they could do more.

b) The Geographical Vulnerability

The geographical vulnerability is also social; therefore, this research included geographical side. People know that they are living in a sloppy area and they are also at risk of earthquakes. While comparing the Nepal's geographical location, 68 percent of the land is covered by hill. Dhugin is even falling under the category of the hilly area, thus it has a risk of disaster. The land, in the future will be gradually becomes sloppy; that's what one expert said after the earthquake. From his briefing, one could easily analyze that few geographical risks in terms of an earthquake is there, but because of research limitation, and time restraint, I couldn't go further in-depth about geographical vulnerability. The vulnerability, which has a direct impact on resilience to disaster. Because of its geographical location, agriculture has been affecting. Terai became grain basket due to geographical location, but more effort needs in this sloppy areas to do the same thing. This location is nearby Lakuri Bhyanjang, which is a hill, so chances of other disasters such as landslide is high. People have hope for their land that they will expand the agriculture area in the future soon. This type of insecurity about the disaster created vulnerable conditions. Out of 22 , two respondents concerned about geographical location. The first respondent was briefing that this is not safe land to build more than two-story houses as per earthquake expert.

Similarly, vulnerability results from other factors such as debt, poor construction of the house, social inequality, exclusion, and gender are observed in interview time. Members of the sample household leaked such factors but due to lack of time, the researcher couldn't go further in-depth.

\section{Conclusion}

In summary, absorbing capacity of household with the help of resources and assets (land, income, and commodities) is one attribute of household resilience. Another attribute is adopting shocks by shifting occupation. Household or household members 
who show their absorbing and adopting capacity with help of other supporting components such as their skill, knowledge, asset, and resource, they are resilient to disaster. Poverty is one of the components of vulnerability which is creating a barrier for a resilient household. In the research area, basically landless, homeless (Staying in temporary shelter or hut) people are struggling for two times meal. Homeless were found in a vulnerable condition and less resilient to disaster. Moreover, a geographical vulnerability (which is also social) is reverse part of resilient household because people have to face several challenge to build houses in sloppy land. Also, they are facing a lack of human resources to work on the farm due to geographical risk. Moreover, the summary also deals with vulnerability are interconnected with disaster resilience because high vulnerability leads to a lack of resilience.

\section{References}

Adger et al. (2005). Social-Ecological Resilience to Coastal Disasters. 309, 1 to 5. Retrieved from www.sciencemag.org.

Barnett, J. (2001). Adapting to Climate Change in Pacific Island Countries: The Problem of Uncertainty.

Bonanno, G. (2004). Loss, trauma, and human resilience: Have we underestimated the human capacity to thrive after extremely aversive events? 59, 20. 59, 20.

Carpenter and Gunderson. (2001, June). Coping with Collapse: Ecological and social dynamics in ecosystem management. Bioscience, Volume 51(6), 451-457. Retrieved from https://doi.org/10.1641/00063568(2001)051[0451:CWCEAS]2.0.CO;2

Fritz, C. (1961). Contemporary Social Problems. New York: Haircourt, Brace, and World.

GON. (2018). Disaster Risk Reduction National Strategic Plan of Action 2018-2030. In M. o. Government of Nepal, Disaster Risk Reduction National Strategic Plan of Action

2018-2030 (pp. 3-5). United Nations Development Programme.

IFRC. (2015). What is Vulnerability? The International Federation of Red Cross and Red Crescent.

MoHA. (2018). Disaster Risk Reduction National Strategic Plan of Action, GON, Ministry of Home Affairs Published by UNDP. UNDP.

Moser, C. (1998). The Asset Vulnerability Framework: Reassessing Urban Poverty Reduction Strategies. Volume 26, Issue 1, January 1998, Pages 1-19.

Quarantelli, E. (1998). What is a disaster? Perspectives on the question. 
Rai, P. (2017). Ethnicity, Vulnerability, and Disaster: A Sociological Study of Earthquake of 2015. Mishra Foundation and central department of Sociology.

Redmond, A. D. (2005). Abc of conflict and disasters: Natural Disasters, BMJ, Vol. 330, Pg 1259-1261 (Vol. Vol. 330). BMJ.

Silwal, K. R. (2017). Class structure and Disaster Vulnerability in Nepal: Post Earthquake Analysis. In Disaster and Society (pp. 48-49). Mishra Foundation and Central Department of Sociology.

Twigg, J. (2004). Characteristics of a Disaster-resilient Community, for the DFID Disaster Risk Reduction. Retrieved from http://www.benfieldhrc.org/disaster_studies/projectscommunitydrrindicators/com munity_drr_indicators_index.htm

UNISDR. (2009). UNISDR Terminology on Disaster Risk Reduction, Published by United Nations International Strategy for Disaster Reduction, Geneva. Retrieved from https://www.unisdr.org/files/7817_UNISDRTerminologyEnglish.pdf

Wisner, B. (2004). Assessment of capability and vulnerability. In: Bankoff G, Freaks G, Hilhorst D. (eds.) Mapping vulnerability. 